\title{
Development of a portable electronic device for the detection and indication of fireworks and firecrackers for security personnel
}

\author{
Aaron Don M. Africa, Stephanie Claire T. Alberto, Travis Evan Y. Tan \\ Department of Electronics and Communications Engineering, De La Salle University, Philippines
}

\begin{tabular}{ll}
\hline \hline Article Info & ABSTRACT \\
\cline { 2 - 3 } Article history: & $\begin{array}{l}\text { The use of fireworks and firecrackers to celebrate festivities is a very } \\
\text { common activity in the Philippines. But due to the lack of strict control and } \\
\text { regulation, there are unwanted risks of accidents from occurring due to the } \\
\text { Received Feb 27, } 2020 \\
\text { poor handling and storage conditions of these devices. Proper monitoring is } \\
\text { important to reduce any unnecessary risks imposed on human life and } \\
\text { property. While existing storage monitoring devices exist, the developed } \\
\text { prototype is designed to contain sensors that are more suited in monitoring } \\
\text { the ideal conditions of where the fireworks are stored. Monitoring the climate } \\
\text { conditions on these devices may seem trivial at first, but such climate change } \\
\text { can involve a rapid rise in temperature that can accidentally ignite } \\
\text { the fireworks and deal with catastrophic damage. Another concern is the rise } \\
\text { of humidity that may alter that chemical characteristics of the gunpowder } \\
\text { stored in the fireworks. Such changes may not have any noticeable effects } \\
\text { until it arrives in the consumer that may experience an unwanted and } \\
\text { unintended change in the performance of the fireworks leading to accidents. } \\
\text { Fireworks facility }\end{array}$ \\
Fireworks storage & $\begin{array}{l}\text { Therefore, it is important for this device to properly monitor the surrounding } \\
\text { area then indicate various forms of alarms as a method of redundancy. }\end{array}$
\end{tabular}

Copyright () 2020 Institute of Advanced Engineering and Science. All rights reserved.

\section{Corresponding Author:}

Aaron Don M. Africa,

Department of Electronics and Communications Engineering,

De La Salle University,

2401 Taft Ave., Malate, Manila 1004, Philippines.

Email: aaron.africa@dlsu.edu.ph

\section{INTRODUCTION}

One of the main chemical compositions found in fireworks is black powder [1]. Black powder is used as the main source of fuel for fireworks and is highly flammable. Improper handling and storage of fireworks can lead to accidents from occurring [2]. There are many factors that can increase the risks of accidents from occurring while also factors that would decrease the quality of the fireworks [3].

An increase in the moisture level would result in a significant increase in the burning time of black powder grains [4]. Water commonly would degrade the quality of pyrotechnics due to the creation of multiple side reactions from its presence. An increase in the moisture level of 1-3\% can sufficiently reduce the burning rate by approximately half $[5,6]$.

To store the fireworks safely, they should be kept away from sources of heat and ignition [7]. The use of the temperature sensor and the carbon monoxide sensor would allow the detection of rapid environmental changes and the presence of smokers in the storage location $[8,9]$. 


\section{THEORETICAL CONSIDERATION}

\subsection{Factors that affect the quality}

\subsubsection{Humidity}

Humidity naturally is inversely proportional to temperature. This means as the humidity increases, the temperature decreases. The moisture content is an important factor in the flammability of a material [10]. When a material is in a very dry condition it becomes increasingly flammable [11]. Black powder, a key ingredient for fireworks have a high hygroscopicity, meaning it absorbs high amounts of moisture. High amount of humidity would cause erratic behavior in the fireworks. An environment with humidity below $30 \%$ would expose the material in the possibility of generating a spark and the fire produced would also be bigger. Making humidity a very important factor in making sure that the facility is in good condition. The safe range of relative humidity for storing fireworks is between $30 \%-50 \%$. Thus, the sensor used for the system is set to alarm once the relative humidity levels go below $30 \%$ or beyond $50 \%$.

\subsubsection{Temperature}

The factors considered for the flammability of a material are its autoignition temperature and its heating value. The autoignition temperature or kindling point is the lowest temperature where a material or a substance starts to ignite on its own in a normal environment with no external source of ignition presents like a flame or a spark [12]. While the heating value or heat of combustion of a substance is the amount of heat released when the material is burning [13, 14].

Key ingredients in manufacturing fireworks such as Black Powder, Red Flare Composition, Flash Powder and Green Flare Composition have ignition temperatures ranging from $315-482^{\circ} \mathrm{C}$. While sulfur has an auto-ignition temperature of $232^{\circ} \mathrm{C}$ [15]. Nitrocellulose, on the other hand, has an autoignition temperature ranging from $132^{\circ} \mathrm{C}-148^{\circ} \mathrm{C}$. Corrugated cardboard or paper in general, often used for packing fireworks has an autoignition temperature of $218-246^{\circ} \mathrm{C}$. Paper also has a very high heating value of $6000 \mathrm{BTUs} / \mathrm{lb}$; thus it can easily catch and spread fire. Another factor considered for the study is the welfare of the employees especially since the storage facilities often acts as a work area for the employees as well. Based on the Philippine's Department of Health, having a heat index of $41^{\circ} \mathrm{C}$ already place the employees in great danger thus the temperature sensor limit is set to $41^{\circ} \mathrm{C}$.

\subsubsection{Hydrogen}

Hydrogen is extremely flammable in fact it has the highest rating of 4 in the flammability scale [16]. A mixture of hydrogen and air can start to ignite even with just a small spark that is invisible to a naked eye [17]. Since hydrogen is the most abundant gas in the universe it is used for industrial purposes such as in manufacturing fireworks. Bonds between hydrogen and carbon are broken to provide fuel or energy for the fireworks [18]. Hydrogen also when combined with other elements is used as a green colorant in fireworks. Since the lower explosion limit (LEL) of Hydrogen is at $4.1 \%$ Getting $10 \%$ of the LEL would define the safe amount of Hydrogen in the environment $[19,20]$. In the case of Hydrogen, it is 4,100ppm, when this amount is reached the facility is in danger of experiencing a fire or an explosion [21].

\subsection{GSM}

The Global System for Mobile Communications, or GSM for short, is one of the two major systems available that started from the second-generation $(2 \mathrm{G})$ digital cellular network [22]. The other system being code-division multiple access (CDMA). It maintains a majority in global market share and enjoys a market dominance everywhere except the United States. It is the de-facto standard for $2 \mathrm{G}$ networks to send and receive SMS text messages. GSM employs the use of subscriber identity modules (SIM cards) to identify its users. GSM technology can operate at frequencies of $850 \mathrm{MHz}, 900 \mathrm{MHz}, 1800 \mathrm{MHz}$, and $1900 \mathrm{MHz}$ frequency bands $[23,24]$.

\section{DESIGN PROCEDURES}

Figure 1 displays the overall system block diagram of the firework safety monitoring device. The sensors are integrated and read by the ESP32 microcontroller. The microcontroller is the main hub that bridges the sensors, the graphical user interface, and the alarm system altogether. The microcontroller is powered by a lithium-ion battery that can supply 5 volts and 2 amps of current.

\subsection{Prototype design}

The developed prototype can be seen in Figure 2. Five different sensors are used to monitor the storage conditions of the fireworks. While the LCD display shows the sensor data readings. The alarm system is currently in-active until one of sensor data readings go beyond the specified values. 


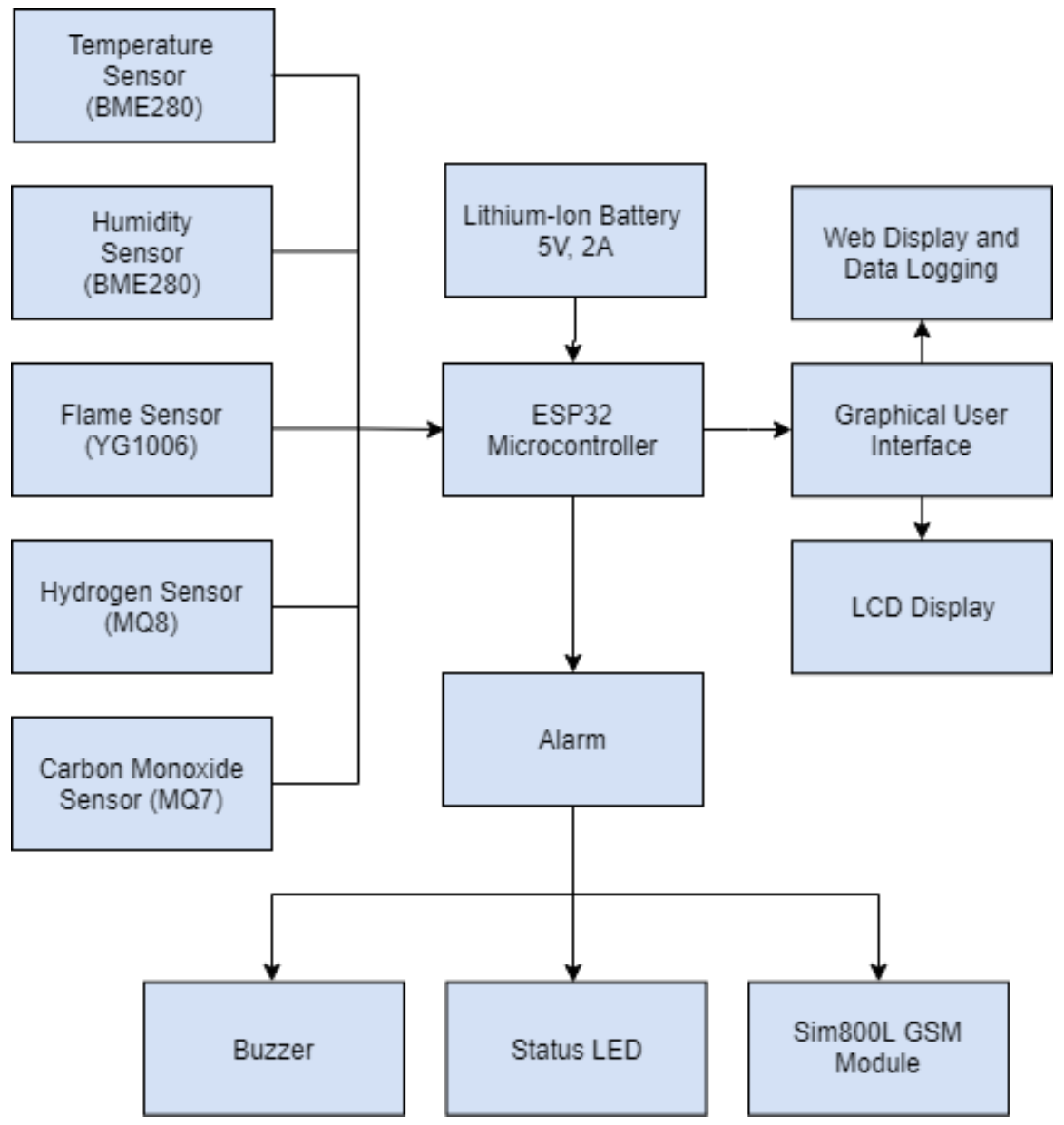

Figure 1. Overall system block diagram

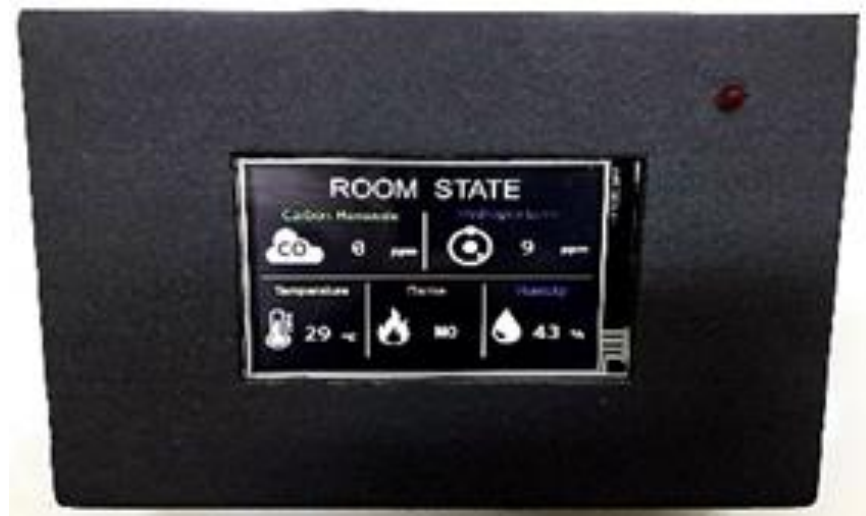

Figure 2. Developed prototype

\subsection{ESP32 nodeMCU}

The researchers implemented the usage of the ESP32 NodeMCU module that utilized the ESP32 microchip developed by Espressif Systems. It is the successor to the popular family of low-cost WiFi microchips-the ESP8266. The researchers chose the ESP32 over the Arduino as the main microcontroller because of it being a smaller and a lower-cost alternative; while also having the ability to connect to the web with its integrated WiFi Module. The ESP32 operates at a clock frequency of $240 \mathrm{MHz}$, and also contains 34 GPIO pins with various features and functionality. 


\subsection{Temperature and humidity sensor}

The BOSCH BME280 is an environmental sensor used to detect humidity, pressure, and temperature. With dimensions of only $2.5 \mathrm{~mm} \times 2.5 \mathrm{~mm} \times 0.93 \mathrm{~mm}$, paired alongside with its capability to consume low amounts of power, the BME280 is a perfect choice to measure the surrounding temperature and humidity needed for the device.

\subsection{Flame sensor}

The flame sensor module is used to detect the presence of fire near the device, at a maximum distance of 1 meter. The infrared sensor of the module is using the YG1006-5mm IR diode, and it is known to be sensitive to both flame and radiation. According to the product page, the IR diode is a high speed and highly sensitive NPN silicon phototransistor; and the black epoxy of the diode provides it with the sensitivity to detect infrared radiation.

\subsection{Hydrogen sensor}

Hydrogen gas obtains the highest rank inflammability in the NFPA 704, a standard created by the National Fire Protection Association of the United States. It poses an unwanted safety risk to the storage location of the fireworks. The MQ8 hydrogen gas sensor is used to detect whether or not its concentrations exceed the assigned safety limits.

\subsection{Carbon monoxide sensor}

Carbon monoxide gas is released during the combustion process of black powder, one of the main chemical compositions used in fireworks. The MQ7 carbon monoxide gas sensor is used as another method to detect if a fire is present or if smokers are in the surrounding vicinity.

\subsection{Sim800L GSM module}

The SIM800L GSM Module is used to send SMS text messages over the cellular network. It can be used to inform individuals even if they are not physically present in the device location. It can be controlled by the microcontroller by using the Hayes or AT command set. Communication occurs between the microcontroller and the module by using the UART serial communication protocol. While the protocol for sending and receiving SMS text messages is done through the general packet radio service (GPRS) data standard for global system for mobile communications (GSM).

\subsection{Lithium-ion battery}

To provide portability to the design, a lithium-ion battery was implemented to the design to power all the available electronics. The battery chosen was developed by Xiao Mi with a total capacity of $10000 \mathrm{mAh}$. It has a supply voltage of 5 volts while also having a maximum current of 2 Amps to power all the available electronics. The chosen battery at a capacity of $10000 \mathrm{mAh}$ is chosen as it can last long hours from the chosen low-power electronics, while also providing the benefit of having a small form factor $[25,26]$.

\subsection{Nextion LCD display}

The Nextion LCD is a human-machine interface (HMI). Simply put, it allows data obtained from the sensors to be easily understood by the users [27]. It is one of the two graphical user interfaces implemented [28, 29].

\subsection{Adafruit IO web interface}

The Adafruit IO web interface is the second graphical user interface created. It operates in a publish and subscribe model. The obtained sensor data is transmitted through the message queuing telemetry transport (MQTT) protocol to be seen across the web. Built-in logging also exists to check back on the status of the device [30-33].

\section{METHODOLOGY}

Part 4 discusses the Methodology. Figure 3 shows the overall system flowchart. 


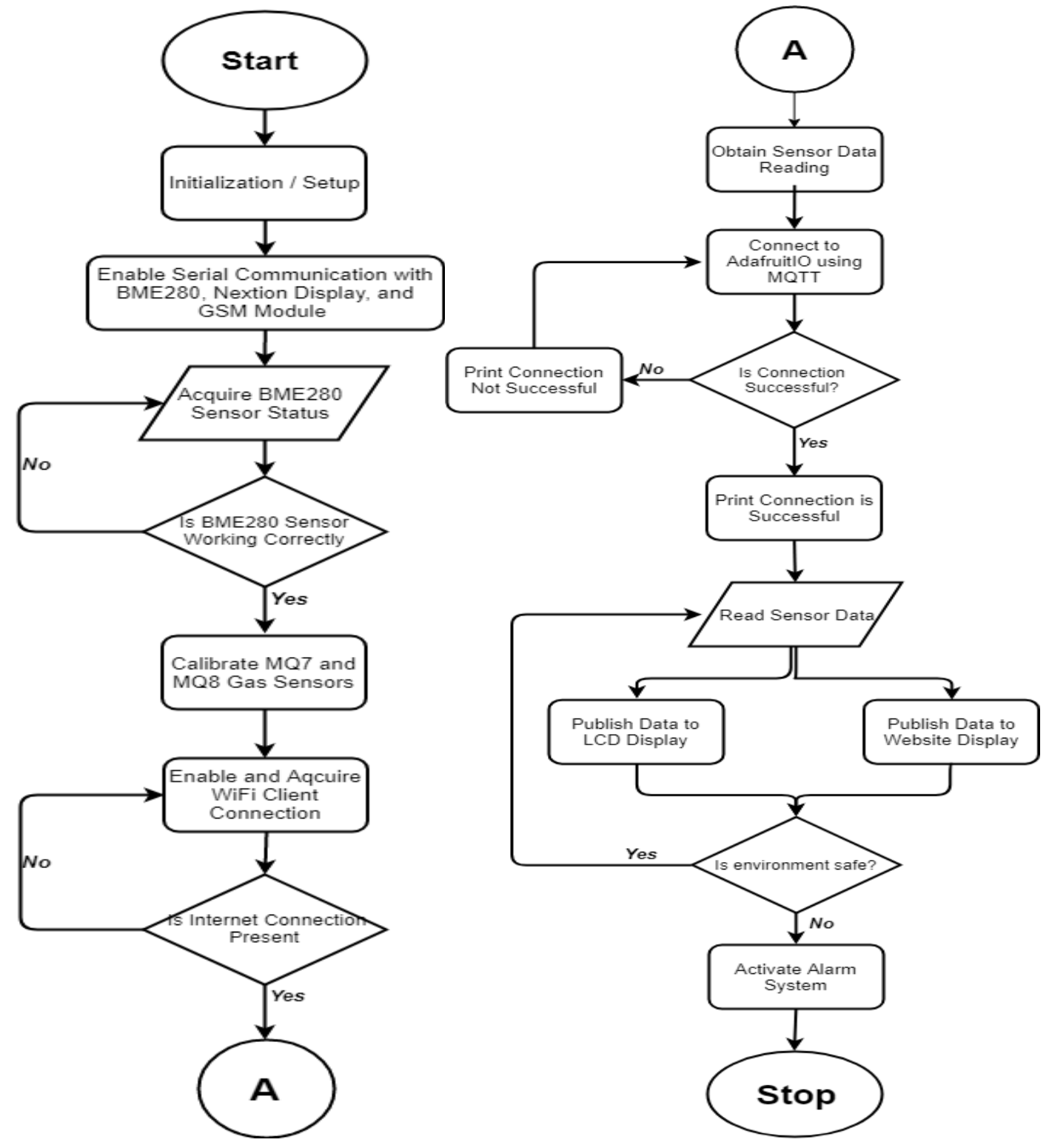

Figure 3. Overall system flowchart part a

\section{RESULTS AND DISCUSSIONS}

\subsection{Technical analysis on temperature and humidity}

To be able to test the reliability and accuracy of the temperature and humidity sensor, the researchers used the system in a total of 7 different environments [34]. 5 of the chosen environments target the reliability of the device in varying environments, which includes a school laboratory, a parking area with poor air circulation, a bakery, a public park, and an open-air food park [35, 36]. Two setups were also made to target the maximum threshold set for the temperature and humidity sensor. To verify the accuracy of the device, the researchers used a separate thermohydrometer and a thermal gun to verify the data gathered by the device. The equation for the Percentage Error was used to compute for the difference between the data obtainsed by the device and the hygrometer $[37,38]$. The average percentage error was used to determine the accuracy of the results obtained $[39,40]$.

The researchers used a blow dryer directed towards the device to reach the limit set which is $41^{\circ} \mathrm{C}$. For the humidity sensor, the researchers used the water vapor gathered from a boiling water set-up for the device to reach the danger levels set for the humidity sensor. Using the formula for the percent error, the students were able to conclude that the temperature sensor has an accuracy of $97.9123 \%$ while the humidity sensor achieved an accuracy of $98.63358 \%$ as shown in Figures 4 to 6. 

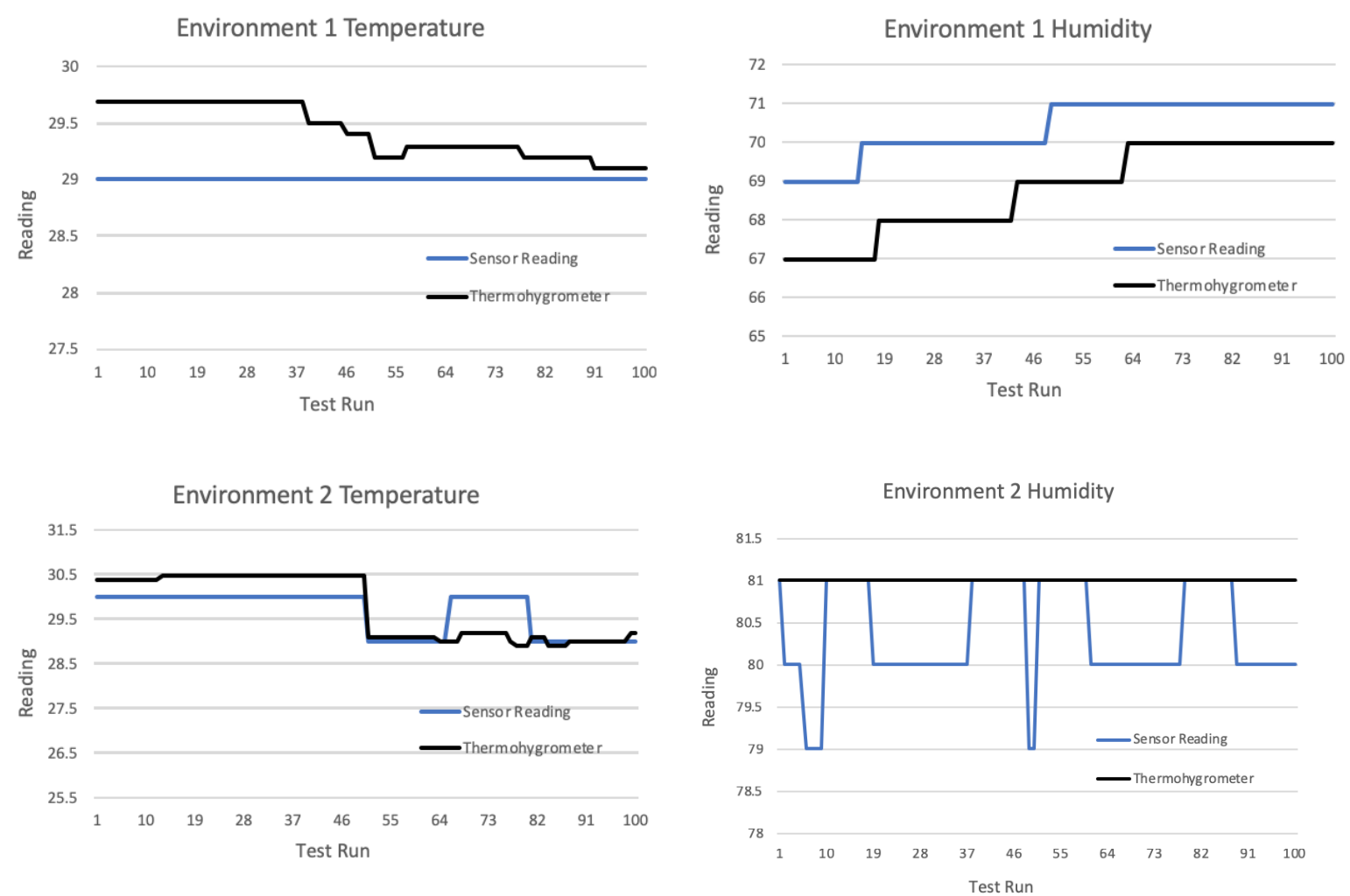

Figure 4. Temperature and humidity for STRC 110 and enrique razon sports complex parking
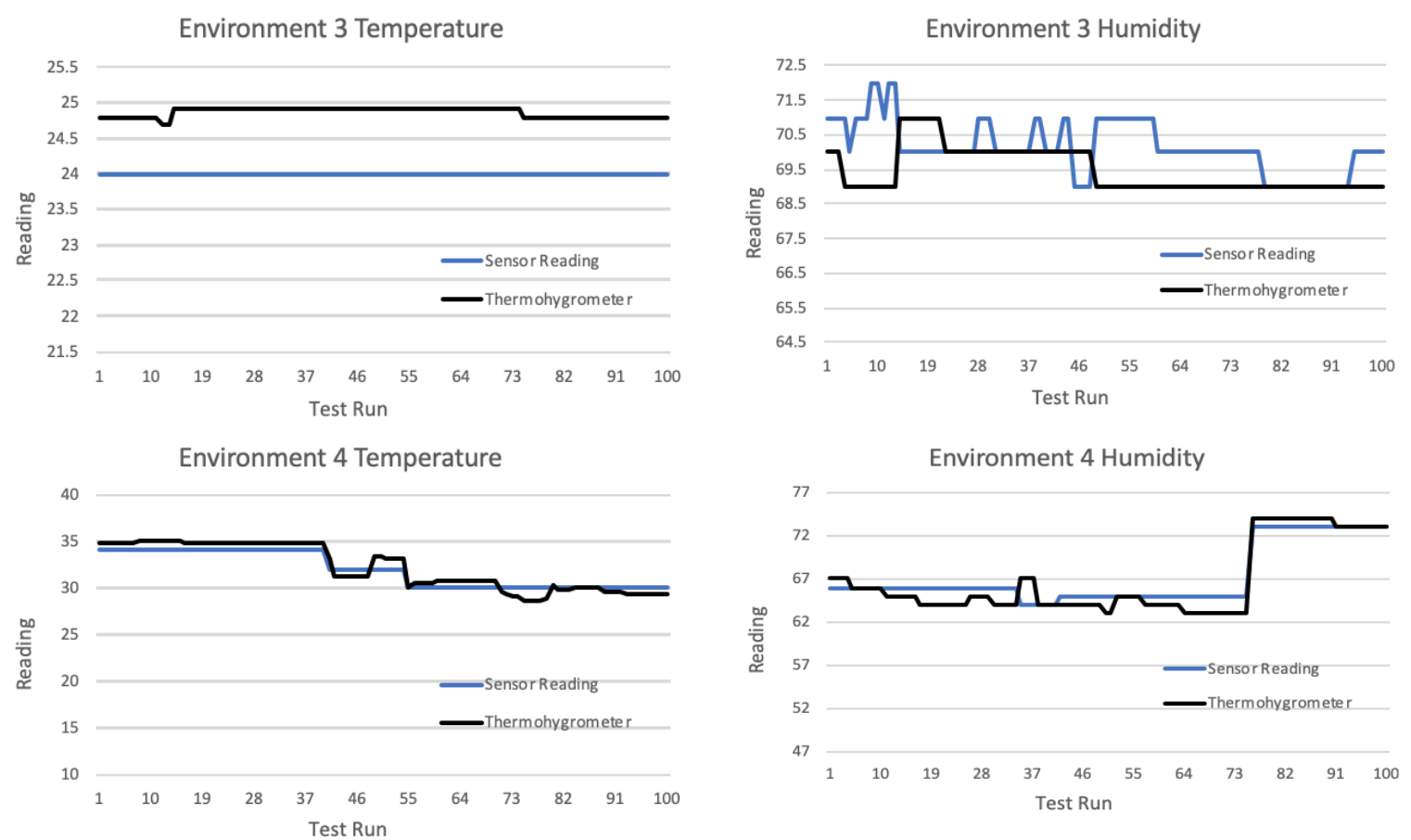

Figure 5. Temperature and humidity for pan de manila bakery and Rizal park 

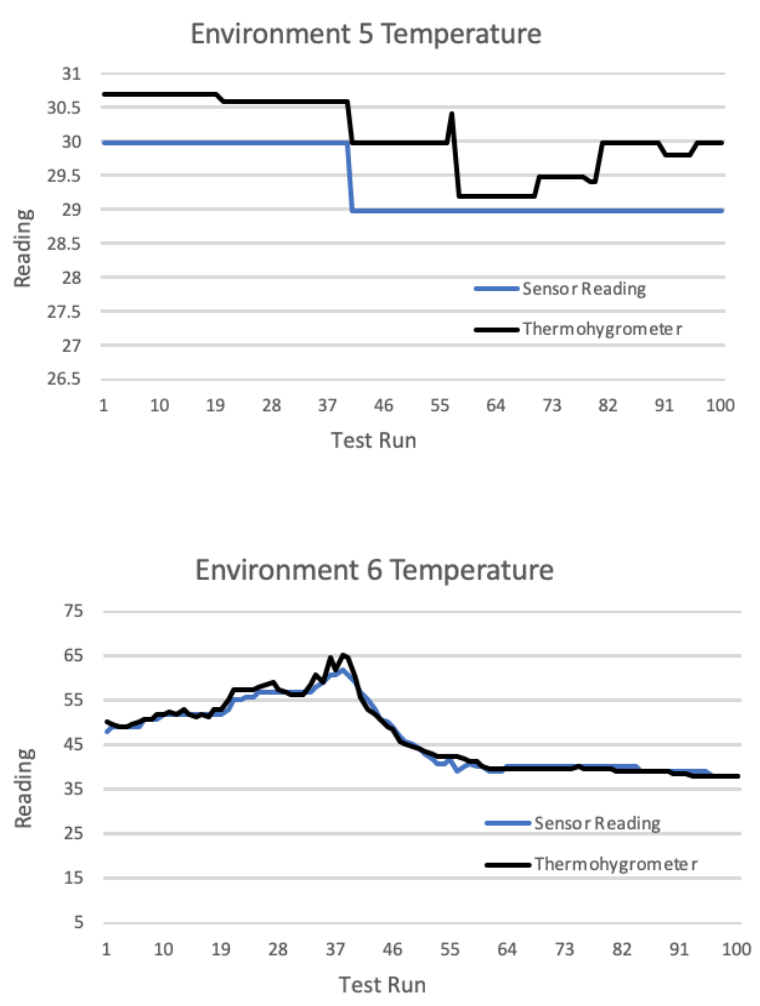
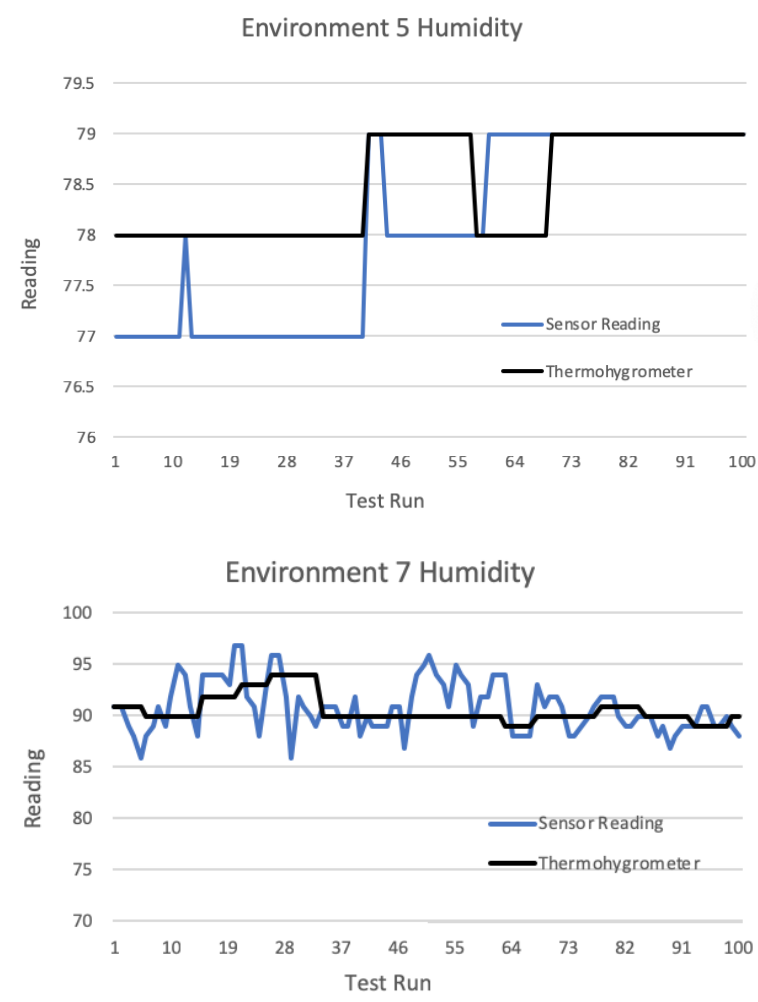

Figure 6. Temperature and humidity for agno Food Park and blow dryer set up

\subsection{Technical analysis on flame detection}

The researchers obtained an average accuracy of $89 \%$ for flame detection at three varying distances, marked at 0 . meters, 1.0 meters and 1.5 meters respectively. However, the inability of detecting the flame was only experienced on the further distance. On the other hand, no false reading of the presence of flame is experienced as shown in Table 1.

Table 1. Flame detection

\begin{tabular}{cccc}
\hline Distance of Flame Sensor & No. of Trial & \multicolumn{2}{c}{ Success Rate } \\
& & Flame Detection & No Flame Detection \\
\hline 0.5 meters & 100 & $100 \%$ & $100 \%$ \\
1.0 meters & 100 & $94 \%$ & $100 \%$ \\
1.5 meters & 100 & $73 \%$ & $100 \%$ \\
Average & & $89 \%$ & $100 \%$ \\
\hline
\end{tabular}

\subsection{Technical analysis on the hydrogen sensor}

To be able to test the MQ8 sensor in Figure 7, the researchers made an electrolysis set-up. Upon starting the electrolysis procedure, the Hydrogen reading reacts accurately. The Hydrogen count gathered in clean air also agrees with the theoretical amount of Hydrogen in clean Air.

\subsection{Technical analysis on the carbon monoxide sensor}

The easiest way to make Carbon Monoxide is through the burning of paper. Upon exposing the system to the burning paper set-up the readings were able to clearly show the reaction. The value obtained also proved the theoretical study that for the presence of smoke a minimum of $100 \mathrm{ppm}$ of Carbon Monoxide should be read. And for clean air, $0-10 \mathrm{ppm}$ is the theoretical amount of Carbon monoxide, which the readings on the device agree with.

\subsection{SMS technical analysis}

The testing for the response time of the SMS feature of the device showed that the time the notification is received is correlated with the strength of the signal both on the receiving and sending ends. Moreover, the 
baseband testing was performed in an area with a fair signal strength of $-97 \mathrm{dBm}$ with an average of 8.50 seconds response time which was also used as the standard for the device as shown in Table 2. The MQ8 sensor readings and Baseline testinh Histogram are shown in Figures 7 and 8 respectively.

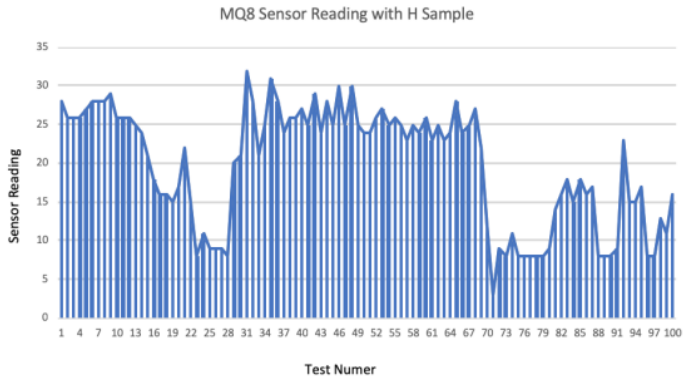

MQ8 Sensor Reading in Clean Air

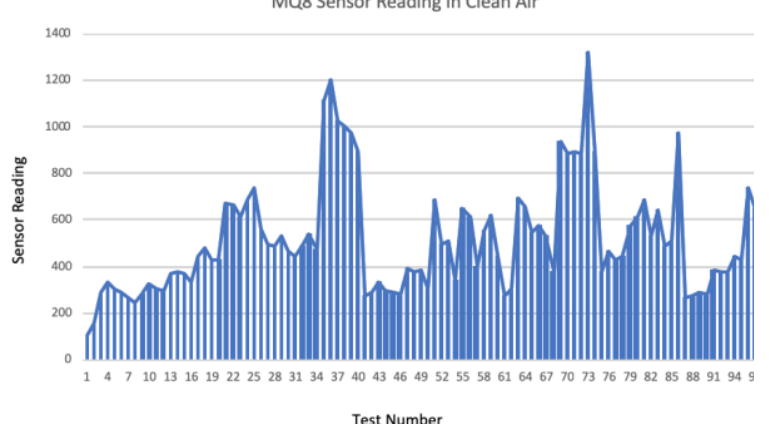

Test Number
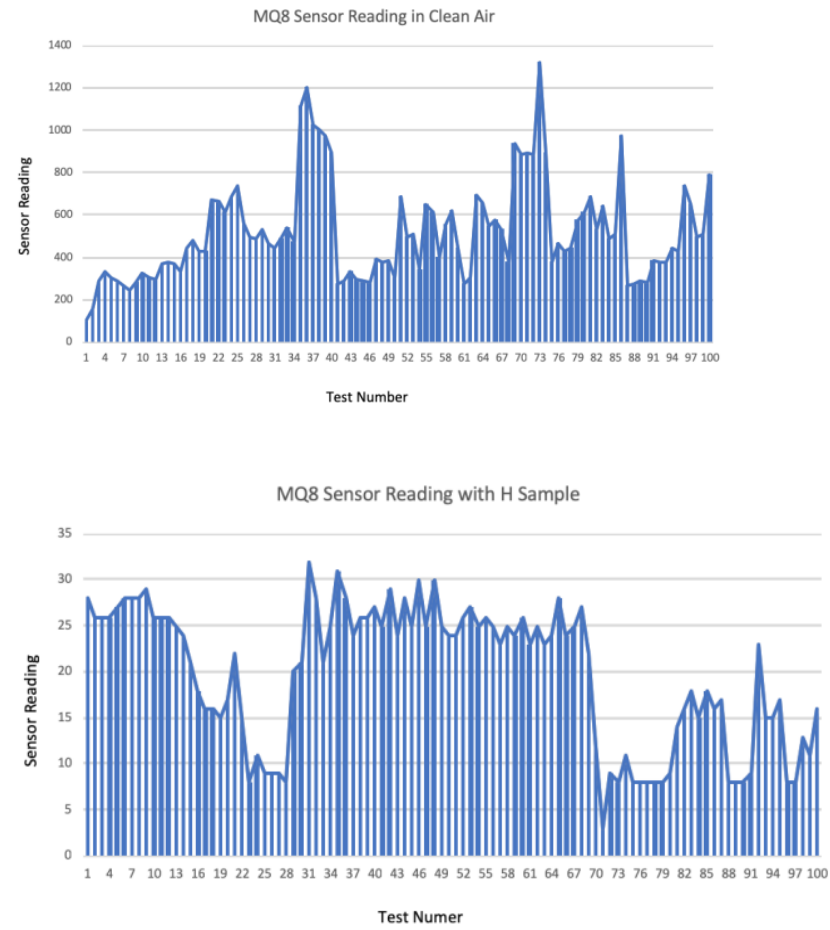

Figure 7. MQ8 sensor readings

Table 2. SMS testing

\begin{tabular}{cc}
\hline Signal Strength & Average Time \\
\hline High & 6.90 seconds \\
Normal & 8.97 seconds \\
Low & 10.91 seconds \\
\hline
\end{tabular}

Baseline Testing

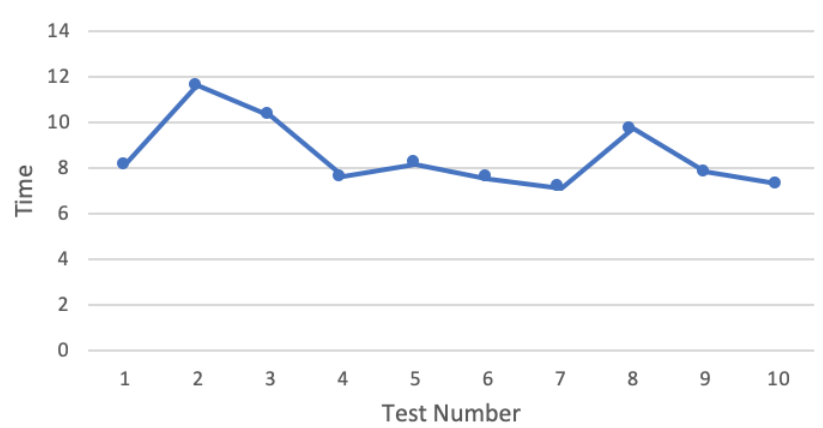

Figure 8. Baseline testing histogram

\section{CONCLUSION}

This research paper provided a means to develop a low-cost device that can safely monitor the storage conditions of fireworks. This prototype has the ability to detect fireworks which can be used by industry personel. The developed prototype could display sensor data readings through its LCD display and through a web interface, while also having logging features that can store sensor data readings. The research is also accurate as it gives the correct readings. Once the storage location is determined to no longer be suited to ideally store fireworks, the alarm system is then activated. An SMS text message is sent by the Sim800L GSM Module, and the audio and visual alarms are also triggered. The system developed is low cost meaning it can be easily reproduced with a low price. 


\section{REFERENCES}

[1] M. Colahan, D. Young, M. Singer, R. P.Nogueira, "Black powder formation by dewing and hygroscopic corrosion processes," Journal of Natural Gas Science and Engineering, vol. 56, pp. 358-367, 2018.

[2] H. Zhang, Q. Zheng, D. Yu, N. Lu, S. Zhang, "Numerical simulation of black powder removal process in natural gas pipeline based on jetting pig," Journal of Natural Gas Science and Engineering, vol. 58, pp. 15-25, 2018.

[3] Y. Huang, C. Xu, H. Li, Z. Jiang, Z. Gong, X. Yang, Q. Chen, "Utilization of the black tea powder as multifunctional admixture for the hemihydrate gypsum," Journal of Cleaner Production, vol. 210, pp. 231-237, 2019.

[4] A. S. Chajistamatiou, E. B. Bakeas, "Identification of thiocyanates by Gas Chromatography-Mass Spectrometry in explosive residues used as a possible marker to indicate black powder usage," Talanta, vol. 195, pp. 456-462, 2019.

[5] N. Kharoua, M. Alshehhi, L. Khezzar, A. Filali, "CFD prediction of Black Powder particles' deposition in vertical and horizontal gas pipelines," Journal of Petroleum Science and Engineering, vol. 149, pp. 822-833, 2017.

[6] T. S. Khan, M. Alshehhi, S. Stephen, L. Khezzar, "Characterization and preliminary root cause identification of black powder content in a gas transmission network-A case study," Journal of Natural Gas Science and Engineering, vol. 27, pp. 769-775, 2015.

[7] Y. Chen, L. Li, X. Zhao, J. Xiao, Q. Wu, Y. Tan, "Simplified hybrid fireworks algorithm," Knowledge-Based Systems, vol. 173, pp. 128-139, 2019.

[8] H. Brink, R. Otjes, E. Weijers, "Extreme levels and chemistry of PM from the consumer fireworks in the Netherlands," Atmospheric Environment, vol. 212, pp. 36-40, 2019.

[9] H. O. Andradottir, T. Thorsteinsson, "Repeated extreme particulate matter episodes due to fireworks in Iceland and stakeholders' response,"Journal of Cleaner Production, vol. 236, p. 117511, 2019.

[10] R. Sheshamani Singh, G. Gupta, S. Yadav, P. K. Dubey, V. N. Ojha, A. Kumar, "Highly-sensitive potassiumtantalum-niobium oxide humidity sensor," Sensors and Actuators A: Physical, vol. 295, pp. 133-140, 2019.

[11] B. Li, L. Hua, Y. Tu, R. Wang, "A Full-Solid-State Humidity Pump for Localized Humidity Control," Joule, vol. 3, no. 6, pp. 1427-1436, 2019.

[12] A. Hayat, A. Hussain, H. Farooq Afridi, "Determination of in-field temperature variations in fresh HMA and corresponding compaction temperatures," Construction and Building Materials, vol. 216, pp. 84-92, 2019.

[13] Q. Shu, S. Dai, H. Nie, W. Yi, "Dynamic temperature compensation model based on nonuniform temperature field change," Infrared Physics \& Technology, vol. 101, pp. 25-31, 2019.

[14] N. Qu, Y. Liu, M. Liao, Z. Lai, F. Zhou, P. Cui, T. Han, D. Yang, J. Zhu, "Ultra-high temperature ceramics melting temperature prediction via machine learning," Ceramics International, vol. 45, no. 15, pp. 18551-18555, 2019.

[15] C. Zhou, B. Ye, Y. Song, T. Cui, P. Xu, L. Zhang, "Effects of internal hydrogen and surface-absorbed hydrogen on the hydrogen embrittlement of X80 pipeline steel," International Journal of Hydrogen Energy, vol. 44, no. 40, pp. 22547-22558, 2019.

[16] L. Huang, G. Liu, "Optimization of the hydrogen separator based on the hydrogen network integration," Journal of Cleaner Production, vol. 235, pp. 1399-1408, 2019.

[17] H. Yu, J. S. Olsen, A. Alvaro, L. Qiao, J. He, Z. Zhang, "Hydrogen informed Gurson model for hydrogen embrittlement simulation," Engineering Fracture Mechanics, vol. 217, p. 106542, 2019.

[18] M. Fiedrich, R. Kurtenbach, P. Wiesen, J. Kleffmann, "Artificial O3 formation during fireworks," Atmospheric Environment, vol. 165, pp. 57-61, 2017.

[19] N. B. Hampson, K. L. Hauschildt, K. Deru, L. K. Weaver, "Carbon monoxide poisonings in hotels and motels: A "silent" epidemic," Preventive Medicine Reports, vol. 16, p. 100975, 2019.

[20] G. Reumuth, Z. Alharbi, K. Siamak Houschyar, B. Kim, F. Siemers, P. Christian Fuchs, G. Grieb, "Carbon monoxide intoxication: What we know," Burns, vol. 45, no. 3, pp. 526-530, 2019.

[21] K. E. McRae, J. Pudwell, N. Peterson, G. N. Smith, "Inhaled carbon monoxide increases vasodilation in the microvascular circulation," Microvascular Research, vol. 123, pp. 92-98, 2019.

[22] R. Tadayoni, A. Henten, J. Sørensen, "Mobile communications-On standards, classifications and generations," Telecommunications Policy, vol. 42, no. 3, pp. 253-262, 2018.

[23] R. Gröning, S. Remmerbach, A. C.Jansen, "Telemedicine: Insulin pump controlled via the Global System for Mobile Communications (GSM)," International Journal of Pharmaceutics, vol. 339, no. 1-2, pp. 61-65, 2007.

[24] A. Africa, S. Bautista, F. Lardizabal, J. Patron, and A. Santos, "Minimizing Passenger Congestion in Train Stations through Radio Frequency Identification (RFID) coupled with Database Monitoring System," ARPN Journal of Engineering and Applied Sciences, vol. 12, no. 9, pp. 2863-2869, 2017.

[25] C. Yan, X. Zhang, J. Huang, Q. Liu, Q. Zhang, "Lithium-Anode Protection in Lithium-Sulfur Batteries," Trends in Chemistry, vol. 1, no. 7, pp. 693-704, 2019.

[26] C. Jo, S. Myung, "Efficient recycling of valuable resources from discarded lithium-ion batteries," Journal of Power Sources, vol. 426, pp. 259-265, 2019.

[27] J. Chen, Y. Chen, T. Chen, Y. Kuo, "Applying two-phase adaptive genetic algorithm to solve multi-model assembly line balancing problems in TFT-LCD module process," Journal of Manufacturing Systems, vol. 52, part A, pp. 86-99, 2019.

[28] A. Akcil, I. Agcasulu, B. Swain, "Valorization of waste LCD and recovery of critical raw material for circular economy: A review," Resources, Conservation and Recycling, vol. 149, pp. 622-637, 2019.

[29] Q. Lu, Q. Fu, L. Luo, Q. Yuan, W. Hua, Y. Yunguang, "Measurement method of LCD surface deformation for smartphone based on optical vision sensing system," Optik, vol. 172, pp. 1079-1088, 2018. 
[30] Q. Feng, B. Engel, D. Flanagan, C. Huang, H. Yen, L. Yang, "Design and development of a web-based interface for the Agricultural Policy Environmental eXtender (APEX) model," Environmental Modelling \& Software, vol. 111, pp. 368-374, 2019.

[31] E. Guven-Maiorov, A. Hakouz, S. Valjevac, O. Keskin, C. Tsai, A. Gursoy, R. Nussinov, "HMI-PRED: A Web Server for Structural Prediction of Host-Microbe Interactions Based on Interface Mimicry," Journal of Molecular Biology, vol. S0022-2836, no. 20, pp. 30089-30098, 2020.

[32] L. Pham, S. Watford, K. Friedman, J. Wignall, A. Shapiro, "Python BMDS: A Python interface library and web application for the canonical EPA dose-response modeling software," Reproductive Toxicology, vol. 90, pp. 102-108, 2019.

[33] J. Garant, J. Perreault, M. Scott, "G4RNA screener web server: User focused interface for RNA G-quadruplex prediction," Biochimie, vol. 151, pp. 115-118, 2018.

[34] Y. Li, "Temperature and humidity sensors based on luminescent metal-organic frameworks," Polyhedron, vol. 179, p. 114413, 2020

[35] R. Zhai, Z. Yang, Y. Zhang, Z. Lv, B. Feng, "Effect of temperature and humidity on the flammability limits of hydrocarbons," Fuel, vol. 270, p. 117442, 2020.

[36] P. Yu, Y. Duan, Q. Fan, S. Tang, "Improved MPS model for concrete creep under variable humidity and temperature," Construction and Building Materials, vol. 243, p. 1181183, 2020.

[37] N. Meng, T. Li, J. Wang, Y. Jia, Q. Liu, H. Qin, "Synergetic cascade-evaporation mechanism of a novel building distributed energy supply system with cogeneration and temperature and humidity independent control characteristics," Energy Conversion and Management, vol. 209, p. 1126629, 2020.

[38] J. Cai, L. Pei, "The Design of A Digital Timing Automatic Feeder With Adjustable Temperature and Humidity," Procedia Computer Science, vol. 166, pp. 366-370, 2020.

[39] L. Torrizo, A. Africa, "Next-hour electrical load forecasting using an artificial neural network: Applicability in the Philippines," International Journal of Advanced Trends in Computer Science and Engineering, vol. 8, no. 3, pp. 831-835, 2019.

[40] A. Africa, A. Alcantara, O. Lagula, A. Latina, C. Te, "Mobile phone graphical user interface (GUI) for appliance remote control: An SMS-based electronic appliance monitoring and control system," International Journal of Advanced Trends in Computer Science and Engineering, vol. 8, no. 3, pp. 487-494, 2019.

\section{BIOGRAPHIES OF AUTHORS}

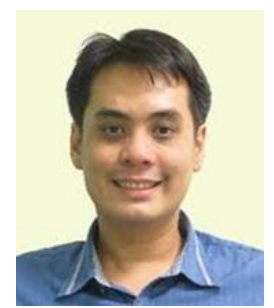

Aaron Don M. Africa is a researcher in the field of Communications Network Engineering. $\mathrm{He}$ is one of the most promising researchers in that area. His area of expertise are Communications Network Engineering, Expert Systems, Control Systems, Network Design, Optimization. Specifically, he deals with the Optimization of Communication Systems to make them more efficient in functionality. This is for these systems to adapt effectively in the industry. He creates simulation models to replicate different scenarios in Network design.

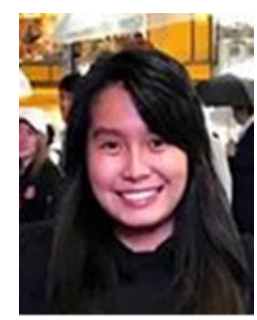

Stephanie Claire T. Alberto was born in Manila, Philippines. She is a grduate of the B.S. degree in electronics and communications engineering (ECE) from De La Salle University, Manila in 2019. She is a member of the electronics and communications engineering society (ECES) and her research interests include Data Communications.

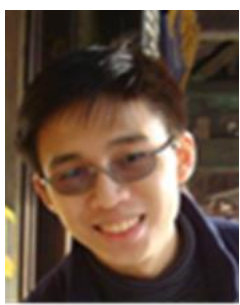

Travis Evan Y. Tan was born in Manila, Philippines. He is a grduate of the B.S. degree in electronics and communications engineering (ECE) from De La Salle University, Manila in 2019. He is a member of the electronics and communications engineering society (ECES) and her research interests include Artificial Intellegence. 